\title{
Inhibition of Early and Late Events of the HIV-1 Replication Cycle by Cytoplasmic Fab Intrabodies against the Matrix Protein, p17
}

\author{
Reuven Levin,* Abner M. Mhashilkar,* Tatyana Dorfman,**** \\ Anatoly Bukovsky,*** Christy Zani, **** Jessamyn Bagley,**** \\ Jorma Hinkula, ${ }^{\ddagger}$ Mattias Niedrig, ${ }^{\S}$ Jan Albert, ${ }^{\ddagger}$ Britta Wahren, ${ }^{\ddagger}$ \\ Heinrich G. Göttlinger, ${ }^{* * *}$ and Wayne A. Marasco ${ }^{\dagger}$ \\ *Division of Human Retrovirology, Dana-Farber Cancer Institute and \\ Departments of $* *$ Pathology and ${ }^{\dagger}$ Medicine, Harvard Medical School, \\ Boston, Massachusetts, U.S.A. ${ }^{\ddagger}$ Microbiology and Tumor Biology \\ Center, Karolinska Institute and Swedish Institute for Infectious \\ Disease Control, Stockholm, Sweden § Robert Koch Institute, \\ Berlin, Germany
}

\begin{abstract}
Background: The HIV-1 matrix (MA) protein, p17, contains two subcellular localization signals that facilitate both nuclear import of the viral preintegration complex early during infection and virus particle assembly late in infection. The dual role of MA in both the afferent and efferent arms of the HIV-1 life cycle makes it an important target for intracellular immunization-based gene therapy strategies.

Materials and Methods: Here we report, using a new bicistronic vector, that an intracellular Fab antibody, or Fab intrabody, directed against a carboxy-terminal epitope of MA from the Clade B HIV-1 genotype, can inhibit HIV-1 infection when expressed in the cytoplasm of actively dividing $\mathrm{CD}^{+} \mathrm{T}$ cells.
\end{abstract}

Results: Marked inhibition of proviral gene expression occurred when single-round HIV-1 CAT virus was used for infections. In challenge experiments using both laboratory strains and syncytium-inducing primary isolates of HIV-1, a substantial reduction in the infectivity of virions released from the cells was also observed.

Conclusions: This novel strategy of simultaneously blocking early and late events of the HIV-1 life cycle may prove useful in clinical gene therapy approaches for the treatment of HIV-1 infection and AIDS, particularly when combined with genetic or pharmacologic-based strategies that inhibit other HIV-1 target molecules simultaneously.

\section{INTRODUCTION}

Gene therapy for the treatment of HIV-1 infection and AIDS has captured the interest of a number of investigators as an attractive addition

Address correspondence and reprint requests to: Wayne A. Marasco, Dana-Farber Cancer Institute, 44 Binney Street, Boston, MA 02115, U.S.A. E-mail: wayne_marasco@dfci.harvard.edu

Reuven Levin's present address is Israel Institute for Biological Research, Ness Ziona 70450, Israel. to conventional pharmacologic therapies because alteration of the host cell could potentially confer permanent suppression of viral replication after infection or perhaps even lasting protection against viral infection. Several strategies have been investigated that have different and sometimes overlapping modes of action. One approach is based on enhancement of the immune response against the virus by using genetically modified cells that express viral gene products to induce antiviral cellular immune responses. An- 
other approach uses an extracellular mode of action by secretion from the transduced cell of a factor directly affecting the HIV-1 life cycle (e.g., sCD4-IgG, anti-gp120 Fab antibody fragments) or of a factor affecting the host's defense mechanism (e.g., a cytokine). Intracellular immunization is a third strategy aimed at the stable transfer of genetic elements that inhibit viral replication, so-called resistance genes, into those cells of a patient that are potential targets for viral infection (1-3).

Intracellular antibodies, or intrabodies, are a recent addition to the field of intracellular immunization-based strategies being used to treat infectious and other diseases (4). As an antiHIV-l treatment strategy, these anti-HIV-l intrabodies are synthesized by the cell and targeted to specific cellular compartments where they bind to their target HIV-1 protein and inhibit its function. Previous intrabodies have prevented HIV-1 replication by blocking gp 120 processing and incorporation into virions $(3,5,6)$, or by inhibiting critical HIV-1 regulatory protein functions such as Tat-mediated viral transcriptional transactivation (7) or Rev-mediated nuclear export of singly spliced or genomic viral RNA (8). However, these approaches do not prevent viral integration into the host genome, as they interrupt the viral life cycle at later stages (4). In a study using intrabodies against HIV-1 RT (9), inhibition of an early event of the viral life cycle, reverse transcription of viral RNA to DNA, was reported. Thus, this approach exhibits tremendous versatility in inhibiting different stages of the viral life cycle by targeting structural, regulatory, and enzymatic proteins of the virus.

Intracellular immunization strategies that are focused on the earliest events of the viral life cycle may offer greater hope for blocking the infection of susceptible cells (preventing the establishment of infection might be more efficient) than strategies aimed at inhibiting gene expression after integration of viral DNA into the cellular genome. Virus uncoating, reverse transcription, transport of the preintegration complex (containing viral DNA) to the nucleus, and subsequent integration of the viral DNA into host chromosomes are all necessary steps that must occur for infection to be established. These early events of the viral life cycle are potential steps that could be inhibited using anti-HIV-1 antibody-based strategies.

To investigate this approach further, we have developed Fab (monovalent antigen binding fragment) intrabodies that are directed against the HIV-1 matrix protein (MA). MA is thought to be involved in two critical stages of the viral life cycle, as it is required for both nuclear import of the viral preintegration complex and for particle assembly. MA contains a nuclear localization signal (NLS) $(10,11)$ and, following acute infection, has been detected in cell fractions containing partially purified HIV-1 preintegration complexes (12) as well as in the nucleus (13). Mutant viruses that show a defect in nuclear import have an impaired ability to infect nondividing cells such as macrophages $(14,15)$. In addition to fulfilling this critical function at an early step of the infection process, MA also plays an essential role in virus morphogenesis. A myristate residue and charged N-terminal amino acids of MA direct gag to the plasma membrane. This targeting is essential for the proper assembly of viral particles $(16,17)$ and for their release into the extracellular space $(18-20)$. In the process, MA also recruits the envelope glycoprotein at the surface of virions (21-23). Molecular explanations for those apparently opposing effects of MA (two subcellular localization signals) have recently been reported (24-26). In this report, we show that cytoplasmic Fab intrabodies against a carboxy-terminal epitope of MA associated with the Clade B HIV-1 genotype are able to inhibit both early and late events of the HIV-1 life cycle.

\section{MATERIALS AND METHODS}

\section{Construction of a Bicistronic Expression Vector}

The $21 \mathrm{H}$ lambda chain (27) was amplified by polymerase chain reaction (PCR) from cDNA using a forward primer containing both a HindIII and NheI site (underlined) $5^{\prime}$ to sequence complementary to the leader of the light chain, 5'-TTTAAGCTT GCTAGCACCATGGCCTGGACCGTTCTC- ${ }^{\prime}$ and a reverse primer containing an $X b a$ I site $3^{\prime}$ to sequence complementary to the light chain constant region, 5'-AAATCTAGACTATGAACATTC TGTAGGGGCCAC-3'. PCR was preformed as previously described (28) and the resultant fragment was cloned into pRc/CMV (cytomegalovirus) (Invitrogen, San Diego, CA) using the HindIII/XbaI sites. The HindIII site was then destroyed by digestion for $2 \mathrm{hr}$ with HindIII, fill-in of the blunt ends with Klenow DNA polymerase, and subsequent relegation.

To PCR amplify the CMV promoter and lambda chain from this construct, a forward primer containing a $5^{\prime} E c o$ RV, PacI, and AscI site, 
5' -TTTGATATCTTAATTAAGGCGCGCCCTTCGC GATGTACGGGCCAG-3' was used with the reverse primer described above. The PCR fragment containing both the promoter and light chain was cloned into the pCMV-Fabl05 vector (6) using the AscI/XbaI sites to form pCMVFabl05/21H.

The internal ribosomal entry site (IRES) corresponding to the $5^{\prime}$ untranslated region (UTR) of the encephalomyocarditis virus (EMCV) was PCR amplified from the pCITE2a vector (Novagen, Madison, WI) using the forward primer, 5'-TTTGCGGCCGCGAA TTAATTCCGGTTA-3' with $5^{\prime}$ NotI site and the reverse primer, $5^{\prime}$-TTT GCTAGCGGTATTATCAT CGTG-3' with $3^{\prime}$ NheI site. The resultant fragment was then cloned into pCMV-Fabl05/21H. In order to create unique sites for cloning light chains into this vector, a PacI linker (New England Biolabs, Beverly, MA) was ligated into the $X b a \mathrm{I}$ site that was first destroyed by digestion for $2 \mathrm{hr}$ with $\mathrm{XbaI}$ and the blunt ends filled in with Klenow DNA polymerase. In order to create unique sites for cloning heavy chains into this vector, the F105 heavy chain was PCR amplified using a forward heavy chain leader primer, 5' -TTTAAGCTTGGC GCGCCACCATGGA ACATCTGTGG-3' containing both HindIII and AscI sites (28) and a reverse human $\mathrm{IgG}_{1} \mathrm{CH}$ primer, 5' -ATTTGCGGCCGCT TATTACGGTGGG CATGTGTGAGT-3' containing a $3^{\prime}$ NotI site. This fragment was then cloned into the pCMVFab105/21H vector containing the IRES sequence.

\section{Construction of Anti-HIV-1 MA Fab Expression Vectors}

The Fd region of the heavy chain and complete kappa chain cDNA fragments from the antiHIV-1 MA hybridoma 3H7 (29) were amplified by PCR and cloned into the AscI/NotI and NheI/ PacI sites of bicistronic vector, respectively. Two versions of the anti-MA Fab3H7 constructs with and without native immunoglobulin leader sequences were designed, amplified, and cloned. Anti-MA heavy chain gene was amplified using the forward leader primer, 5'-ATACTGGCGCGC CACCATGG(C/A)TTGGGTGTGGA(A/C)CTTGCT ATTCCTG-3' or the forward FR l primer, 5'-TTACT GGCGCGCCACCATGATCCAGTTGGTGCAGTCT GGACCT $-3^{\prime}$ and reverse IgG $_{3}$ hinge primer $5^{\prime}$-TC AATGCGGCCGCCTATGGGCATGAAGAACCTG$3^{\prime}$, while the kappa chain gene was amplified using the forward leader primer, 5'-TCATT GCTAGCACCATGGGC(T/A)TCAAGATGGAGTC ACA(T/G)(T/A)(T/C)(T/C)C(T/A)G-3' or forward FR 1 primer, $5^{\prime}$-TTAATGCTAGCACCATGGGAGC TGATGGGAACATTGTA-3' and reverse constant kappa primer 5'-TCGACTTAATTAACTACTAAC ACTCATTCCTGTTGAA-3' (30).

\section{In Vitro Transcription/Translation Assay}

The TNT-coupled reticulocyte lysate system (Promega, Madison, WI) was used for in vitro translation/transcription of the anti-MA Fab intrabody plasmids using T7 RNA polymerase promoter. Briefly, a cocktail comprising rabbit reticulocyte lysate $(25 \mu \mathrm{l})$, reaction buffer $(2 \mu \mathrm{l})$, TNT-T7 RNA polymerase ( $1 \mu \mathrm{l})$, amino acid mixture minus cysteine $1 \mathrm{mM}(1 \mu),\left[{ }^{35} \mathrm{~S}\right]$-cysteine $(1000 \mathrm{Ci} / \mathrm{mmol})$ at $10 \mathrm{mCi} / \mathrm{ml}(4 \mu \mathrm{l})$, and RNasin $40 \mathrm{U} / \mu \mathrm{l}(1 \mu \mathrm{l})$ was increased in volume to $50 \mu \mathrm{l}$ with nuclease-free water, and 0.3-1 $\mu \mathrm{g}$ of DNA was incubated in this reaction mixture at $30^{\circ} \mathrm{C}$ for $90 \mathrm{~min}$. The reaction was stopped by adding $2 \times$ SDS sample buffer containing 2-mercaptoethanol. Proteins were resolved on $12.5 \%$ SDSPAGE and visualized by autoradiography and analyzed for transcription/translation efficiency. Luciferase cDNA and $\mathrm{pRc/CMV}$ vector were used as positive and negative controls, respectively.

\section{Construction of Stably Transfected Cell Lines}

$\mathrm{CD} 4^{+}$Jurkat-T lymphocytic cell lines were cultured at $37^{\circ} \mathrm{C}$ and $5 \% \mathrm{CO}_{2}$ in RPMI- 1640 media containing $2 \mathrm{mM}$ glutamine and supplemented with $10 \%$ fetal calf serum (FCS) and penicillinstreptomycin (P/S) $(100 \mu \mathrm{g} / \mathrm{ml})$. COS- 1 cells and HeLa cells were cultured in Dulbecco's modified Eagle's medium (DMEM) supplemented with $10 \%$ of FCS and P/S. Transfection of these cell lines was performed with the DEAE-dextran method as described previously (7). In brief, Jurkat cells were washed three times with PBS and suspended in $0.8 \mathrm{ml}$ of serum free RPMI medium to which $10 \mu \mathrm{g}$ of anti-MA Fab3H7 plasmid DNA and $125 \mu \mathrm{g}$ of DEAE-dextran were added. The mixture was incubated with the cells for $30 \mathrm{~min}$ at $37^{\circ} \mathrm{C}$. The cells were then washed twice with serum-free RPMI media and plated with RPMI containing $10 \%$ FCS for $60 \mathrm{hr}$, after which they were exposed to $\mathrm{G} 418$ selection $(800 \mu \mathrm{g} / \mathrm{ml})$. After 10 days of selection, the G418-resistant cells were subcloned by limiting dilution and individual stable colonies were propagated and characterized.

COS- 1 cells $\left(10^{7}\right.$ cells $)$ were plated in $100-\mathrm{mm}$ plates $24 \mathrm{hr}$ prior to transfection with DEAE-dextran (7). In brief, $10 \mu \mathrm{g}$ of the various anti-MA Fab3H7 plasmid DNA were diluted with $1.8 \mathrm{ml}$ of PBS and $1 \mathrm{mg}$ of DEAE-dextran was added to the mixture. Cells were washed twice 
with PBS prior to transfection. The mixture containing the DNA and DEAE-dextran was layered on the cells and plates were incubated at $37^{\circ} \mathrm{C}$ for $30 \mathrm{~min}$. The cells were treated with chloroquine (80 $\mu \mathrm{M}$, final concentration) in $5 \mathrm{ml}$ of serumfree DMEM medium and incubated for an additional $2.5 \mathrm{hr}$ at $37^{\circ} \mathrm{C}$. The media were aspirated and replaced by $5 \mathrm{ml}$ of fresh, serum-free DMEM containing 5\% DMSO. After $2.5 \mathrm{~min}$ of further incubation, the media were removed and cells were washed twice with phosphate-buffered saline (PBS), and $8 \mathrm{ml}$ of fresh DMEM medium containing $10 \%$ FCS was added and cells incubated at $37^{\circ} \mathrm{C}$ until further processing by metabolic labeling (48-60 post-transfection) and/or for further analysis (transient expression, etc.).

\section{Radiolabeling and Immunoprecipitation}

For immunoprecipitation, transiently transfected COS-1 cells were starved in cysteine-deficient RPMI media for $2 \mathrm{hr}$ and then metabolically labeled with $50 \mu \mathrm{Ci} / \mathrm{ml}$ of $\left[{ }^{35} \mathrm{~S}\right]$-cysteine. Cells were washed three times with PBS and lysed with $1 \times$ radioimmunoprecipitation assay (RIPA) buffer containing $8 \mathrm{mM} \mathrm{Na} \mathrm{NPO}_{4}, 2 \mathrm{mM}$ $\mathrm{NaH}_{2} \mathrm{PO}_{4}, 140 \mathrm{mM} \mathrm{NaCl}, 1 \%$ nonident P-40, $0.5 \%$ sodium deoxycholate (DOC), and $0.05 \%$ sodium dodeocyl sulfate (SDS) (21). Soluble proteins from the cell lysate were immunoprecipitated with rabbit anti-mouse IgG (Sigma, St. Louis, MO) bound to protein A-sepharose beads. Proteins were resolved on $12.5 \%$ SDS-PAGE and visualized by autoradiography (31).

\section{Detection of Binding Activity of Secreted Anti-MA Fab Fragments}

Enzyme-linked immunosorbent assay (ELISA) was used to measure the binding activity of the secreted anti-MA Fab3H7 fragments. Microtiter plates (Dynatech, Chantilly, VA) were coated with recombinant HIV-1 ${ }_{\mathrm{IIB}}$ MA protein (Agmed, Bedford, MA) at $100 \mathrm{ng} /$ well. After blocking the coated plate with $2 \%$ bovine serum albumin (BSA) in PBS, concentrated media $(10 \times)$ from stably transfected anti-MA expressing Jurkat Fab3H7+L or Jurkat-vector cells were added to the plate. Horseradish peroxidase (HRP)-labeled rabbit anti-mouse IgG (whole molecule, Sigma) was used as the secondary antibody. Bound Fab3H7 fragments were detected by the addition of HRP substrate (TMBmembrane HRP substrate system, Kirkegaard and Perry, Gaithersburg, $M D$ ) and by determining the optical density at $405 \mathrm{~nm}$.

\section{Trans-complementation Assay}

The trans-complementation assay was performed as previously described (32). This assay uses two plasmids, one encoding Rev and Env proteins (pSVIIIenv) under control of HIV-1 long terminal repeat (LTR), and the other containing an HIV-1 provirus with a deletion in the env gene and the bacterial chloramphenicol acetyltransferase (CAT) gene replacing nef gene (pHXB $\Delta$ envCAT). HeLa cells were cotransfected with $20 \mu \mathrm{g}$ pHXB $\Delta$ env CAT plasmid and with $5 \mu \mathrm{g}$ pSVIIIenv plasmid, and the culture medium from the transfected cells that contained released viruses with the capacity for a single round of infectivity $(10,000$ $\mathrm{cpm} / \mathrm{ml} \mathrm{RT}$ of [pHXB $\Delta$ envCAT/pSVIIIenv]) was used to infect stably transfected bulk populations of Jurkat-Fab3H7-L cells or subclones obtained following subcloning by limiting dilution and G418 selection. Seventy-two hours post-infection, the cells were lysed and analyzed for CAT activity according to the manufacturer's instructions (Promega).

\section{Detection of Virus Infection}

Parental Jurkat cells $\left(1 \times 10^{6} \mathrm{cell} / \mathrm{ml}\right)$, stable Jurkat-vector cells, or Jurkat-Fab3H7-L cells were challenged with different multiplicity of infection (MOI) of $\mathrm{HXWIB}_{\mathrm{vpu}+}, \mathrm{HXWIB}_{\mathrm{vpu}-}$, or two synctium-inducing (SI) primary HIV-l isolates (7). Production of viral particles in culture medium was measured by using a radioimmunoassay (RIA) kit for HIV-1 p24 gag antigen (DuPont, Boston, MA) according to the manufacturer's instructions. A standard curve was constructed by using standards supplied in the kit and by extrapolation from radioactivity measured to determine the amount of p24 in the unknown samples.

In challenge experiments with HIV-2, (strain NIH-Z obtained through Advanced Biotechnologies, Columbia, MD), a reverse transcriptase (RT) assay was used to measure viral infection. In brief, supernatants $(1 \mathrm{ml})$ collected on different days after infection were centrifuged at 12,000 $\mathrm{rpm}$ for $\mathrm{l} \mathrm{hr}$. The pellet was resuspended in $10 \mu \mathrm{l}$ of suspension buffer ( $50 \mathrm{mM}$ Tris, $\mathrm{pH} 7.5$, with $1 \mathrm{mM}$ DTT, $20 \%$ glycerol, $0.25 \mathrm{M} \mathrm{KCl}, 0.25 \%$ Triton X-100) and put on dry ice. The samples were frozen and thawed three times, using dry ice and a $37^{\circ} \mathrm{C}$ bath, respectively. The thawed suspension was further mixed with $40 \mu \mathrm{l}$ of RTcocktail mix (10 $\mu$ l $5 \times$ RT buffer [ $250 \mathrm{mM}$ Tris, $\mathrm{pH} 7.5,37.5 \mathrm{mM} \mathrm{MgCl}_{2}, 0.25 \%$ Triton X-100], $1.2 \mu \mathrm{l}$ of DTT, $5 \mu \mathrm{l}$ of Poly A-oligo dT [Boehringer-Mannheim], $1 \mu \mathrm{l}$ of ${ }^{3} \mathrm{H}$-TTP [1 $\mu$ Ci per reac- 
tion, Dupont NEN], and $22.8 \mu \mathrm{l}$ of DEPC-treated water), vortexed, and incubated at $37^{\circ} \mathrm{C}$ for $1 \mathrm{hr}$. After incubation, the mixture was spot inoculated on filter paper discs (Whatmann DE81). The discs were then washed three times with $2 \times$ SSC buffer, followed by two washes with $95 \%$ ethanol. The discs were then air dried and counted in a scintillation counter.

The release of infectious HIV-1 virions from Jurkat-vector and Jurkat-Fab3H7-L cells was investigated by comparing cell-free $\mathrm{TCID}_{50}$ units. Briefly, cell-free supernatants harvested from infected cells were removed and stored at $-70^{\circ} \mathrm{C}$. Supernatants from the first day after infection of cells, when the level of cell-free p24 was $25 \mathrm{ng} / \mathrm{ml}$, were quickly thawed and filtered through a 0.2$\mu \mathrm{m}$ filter prewashed with RPMI containing $2 \%$ FCS. Four-fold dilutions of the supernatant were added to 95-well flat-bottomed microtiter plates containing $\mathrm{CD}^{+} \mathrm{H} 9$ cells $(20,000$ cells/well $)$. Plates were observed every day for 14 days for cytopathic effects, and TCID $_{50}$ units were calculated as described by Johnson and Byington (33).

\section{PCR-based HIV-1 DNA Integration Assay}

A sensitive PCR procedure for detection of integrated HIV-1 DNA was used (34). Digestion of unintegrated viral DNA of the HXIIIB $_{\text {vpu }}$ strain of HIV-1 (whether linear or circular) with SacI produces two large fragments of 5,324 bp and $3,572 \mathrm{bp}$ in size and a series of small fragments $<700 \mathrm{bp}$. There is one Sacl site in both the $5^{\prime}$ and $3^{\prime}$ LTR and there are no XbaI sites in the viral DNA. Digestion of cellular DNA with SacI and $X b a \mathrm{I}$ results in a predictable pattern of restriction fragments except for heterogeneous sizes of the HIV-1 cellular DNA junction fragments. Therefore, the SacI/XbaI-digested cellular DNA was first separated on a $1 \%$ low-melting-point (LMP) agarose gel and extracted in the range of 1 to 3.5 $\mathrm{kb}$, which should contain only junction fragments and not SacI-digested, unintegrated HIV-1 DNA. The isolated $1-3.5 \mathrm{~kb}$ DNA fragments were then subjected to ligation to reconstruct a fullsize LTR. Next, PCR was performed using LTRspecific primers, which resulted in the amplification of a single-size DNA fragment of $561 \mathrm{bp}$. PCR products were resolved on a $1.5 \%$ agarose gel and then transferred to Magna nylon transfer membrane and hybridized with an LTR-specific

${ }^{32} \mathrm{P}$-labeled oligonucleotide probe.

Specifically, high-molecular-weight cellular DNA was isolated from parental and stably transfected Jurkat cells by extraction with the Easy
DNA kit of Invitrogen according to the manufacturer's instructions. Two micrograms of each DNA preparation was subject to double digestion with $S a c I$ and $X b a I$ restriction enzymes overnight at $37^{\circ} \mathrm{C}$, and was electrophoresed on a $1 \%$ LMP agarose gel. DNA was extracted with the rapid Geneclean Kit (Bio 101 II, La Jolla, CA) and was subjected to ligation in the presence of the DNA ligase (New England BioLabs). Ten microliters of the ligation mix was used as a template in a standard PCR (35) with a pair of the HIV-1 LTR specific primers: forward LTR 1 primer for the U3 region (5'-CCT GAT TAG CAG AAC TAC ACA CCA) and reverse AA55 primer (5'-CTG CTA GAG ATT TTC CAC ACT GAC-3') for the R region (36). PCR conditions were $1 \mathrm{~min}$ at $94^{\circ} \mathrm{C}, 1$ min at $55^{\circ} \mathrm{C}$, and $1 \mathrm{~min}$ at $72^{\circ} \mathrm{C}$, and a 30 -sec ramp between each temperature for 40 cycles. The PCR products were resolved in a $1.5 \%$ agarose gel, transferred to Magna nylon transfer membrane (MSI, Westboro, MA), and hybridized with a ${ }^{32} \mathrm{P}$-labeled oligonucleotide M669 probe (26) (5'-GTG TGC CCG TCT GTT GTG TGA CTA TCG TAA -C-5') under standard conditions (35).

In addition to DNA from infected and uninfected cells, three recombinant HIV-1 DNA constructs were used as controls in the procedure: (1) the $\mathrm{HXBc} 2$ plasmid, which contains the $\mathrm{SVC}_{\mathrm{vpu}}+$ provirus, including flanking plasmid DNA sequences bound by XbaI restriction sites that serve as a positive control for integrated HIV-1 (Fig. 4, lane 12); (2) the 680 bp SacI-XhoI HIV-1 LTR fragment excised from the HIV-1 LTR carrying a pU3RIII plasmid, which serves as a marker for digestion fragments smaller than 1 $\mathrm{kb}$; and (3) the SacI-SacI $(5,324 \mathrm{bp}+3,572 \mathrm{bp})$ full-genomic HIV-1 DNA fragment excised from the $\mathrm{HXBc} 2$ plasmid and which serves as a marker for full-length HIV-1 DNA. Marker viral DNAs (2 and 3) were spiked into HIV-1-negative cellular DNA, and the DNA mixture was then analyzed in the HIV-1 DNA integration assay to confirm that the LMP agarose gel separation and elution of DNA removed DNA fragments outside of the desired $1-3.5 \mathrm{~kb}$ range.

\section{RESULTS}

\section{Construction of a Bicistronic Expression Vector and Expression of Secreted Anti-MA Fab3H7 Fragments}

A bicistronic expression vector pCMV-Fab-IRES under the control of the cytomegalovirus immediate early (CMVIE) promoter was constructed 


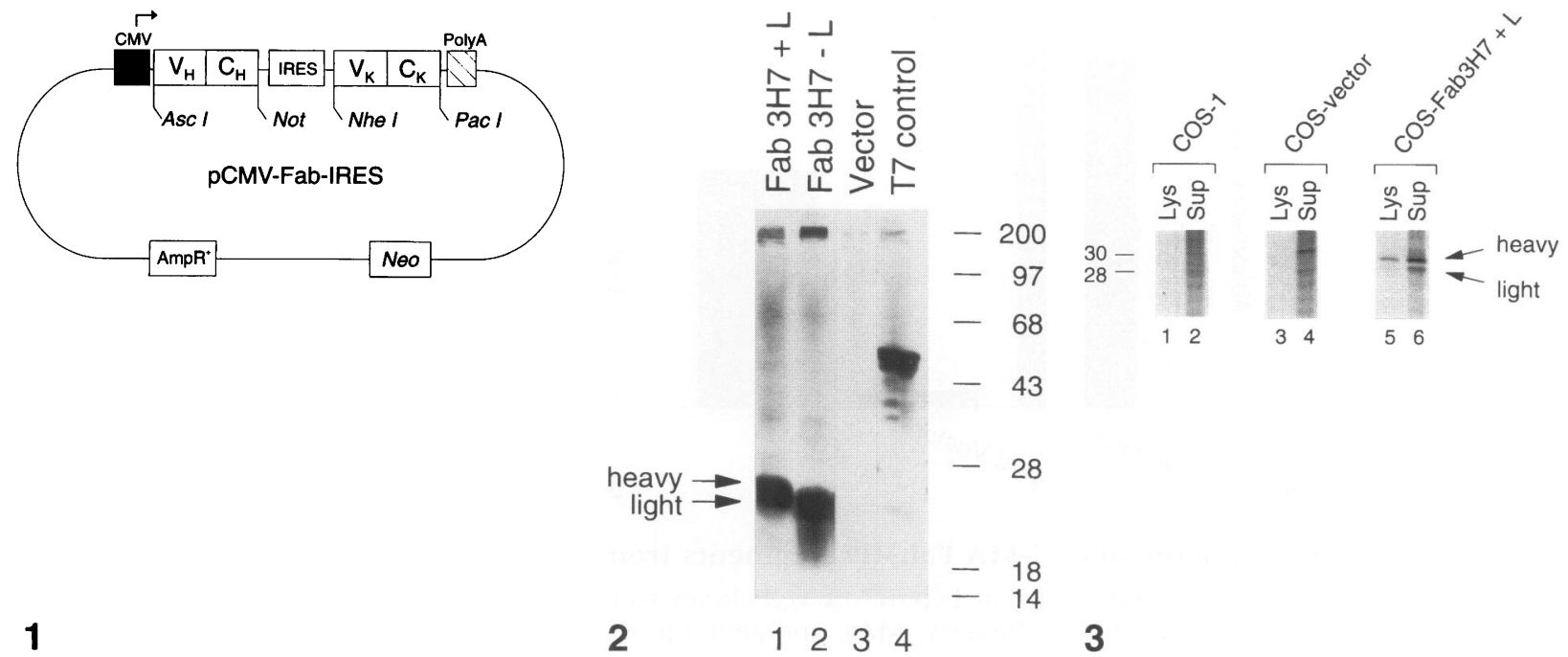

FIG. 1. Design of bicistronic expression vector pCMV-Fab-IRES for simultaneous expression of Fd heavy and light chains of Fab intrabodies

FIG. 2. Expression of anti-MA Fab3H7 fragments in a rabbit reticulocyte lysate system

$\left[{ }^{35} \mathrm{~S}\right]$-cysteine-labeled proteins were synthesized in rabbit reticulocyte lysate and were analyzed by electrophoresis on a $12.5 \%$ SDS-PAGE gel. The gel is a 4-hr autoradiograph. Lane 1: pRc/CMV plasmid expressing anti-MA Fab3H7 fragments with native immunoglobulin leader sequences; lane 2: pRc/CMV plasmid expressing anti-MA Fab3H7 fragments without native immunoglobulin leader sequences; lane 3: pRc/CMV control plasmid; lane 4: luciferase cDNA as T7 positive control. Arrows indicate Fd heavy and light chains.

FIG. 3. Immunoprecipitation of Fab3H7 fragments from stably transfected COS-1 cells

$\left[{ }^{35} \mathrm{~S}\right]$-cysteine-labeled proteins from the cell lysate or culture medium of parental COS-1 cells. COS-pRc/CMV-vector, or COS-Fab3H7+L cells were immunoprecipitated with rabbit anti-mouse IgG and were analyzed by electrophoresis on a 12.5\% SDS-PAGE gel. Lanes 1, 3, 5: cell lysate; lanes 2, 4, 6: cell supernatant. Lanes 1 and 2: parental COS-1 cells; lanes 3 and 4: COS-pRc/CMV-vector cells; lanes 5 and 6: COS-Fab3H7+L cells (clone 15/72).

Arrows indicate Fd heavy and light chains

that allows the near stoichiometric coexpression of the Fd-heavy and complete light chain of an Fab fragment (Fig. 1). An internal ribosomal entry site (IRES) corresponding to the $5^{\prime}$ untranslated leader region (UTR) of encephalomyocarditis virus (EMCV) $(37,38)$ was used to obtain CAP-independent ribosomal binding and highlevel translation of the light chain. The binding site of the 3H7 MAb used in these studies has been previously epitope mapped to the amino acid sequence KKAQQAAADT (residues 113-122) near the carboxy-terminus of MA (29). This epitope is associated with the Clade B HIV-1 genotype (39), including well-studied laboratory strains such as LAI, MN, SF2, and RF, as well as a majority of European and North American isolates. Isolates of Clade $\mathrm{B}$ may be distributed globally (39).

To determine if the Fd heavy and kappa light chains of the Fab3H7 fragments could be expressed in this bicistronic vector, in vitro transcription and translation were performed using a rabbit reticulocyte system. As shown in Fig. 2, the Fd heavy and light chains were expressed in near stoichiometric amounts, regardless of whether the native immunoglobulin leader sequences were present to allow secretion (lane 1) or absent to allow cytoplasmic expression (lane 2).

COS-1 cells were next transfected by DEAEdextran with the pRc/CMV-Fab3H7+L plasmid, which encodes the Fd heavy and kappa chains of Fab3H7 with their native immunoglobulin leader sequences intact. Stably transfected COSFab3H7+L cells were generated with G418 selection, single-cell subclones were obtained by limiting dilution, and mouse Ig was detected using radioimmunoprecipitation of ${ }^{35} \mathrm{~S}$-cysteinelabeled proteins with rabbit anti-mouse IgG. In stably transfected COS-Fab3H7+L cells, two protein bands (approximately 30 and $28 \mathrm{kd}$ ) that corresponded to the Fd heavy and kappa chains of Fab3H7 were detected in the lysate and culture medium, while corresponding bands were not detected in parental COS-1 cells or in pRc/ 

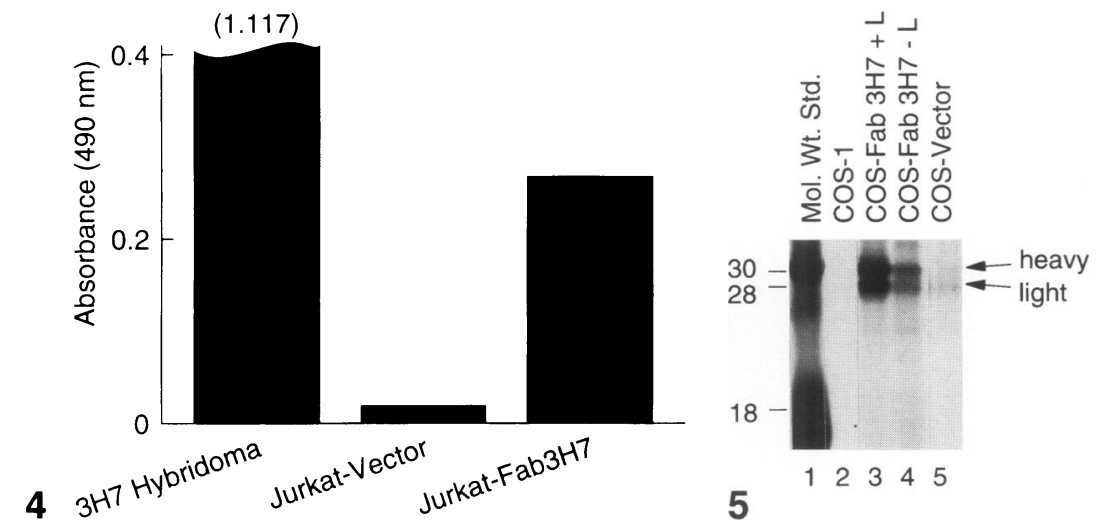

FIG. 4. Secretion of functional anti-MA Fab3H7 fragments from stable $\mathrm{CD}^{+}{ }^{+} \mathrm{Jurkat}^{\mathrm{T}}$ cells

Fresh medium from individual stable Jurkat-Fab3H7 + L cell clones were harvested after 24 hr incubation, concentrated $10 \times$ in an Amicon concentrator (Beverly, MA), and added to ELISA wells in triplicate that were coated with recombinant HIV-1 MA (Agmed) at $100 \mathrm{ng} /$ well. Binding of Fab3H7 fragments was detected by HRP-labeled rabbit anti-mouse IgG as the secondary antibody and the standard deviations were $<5 \%$. Supernatants from the following sources were tested: Lane 1: $3 \mathrm{H} 7$ hybridoma cells; lane 2: Jurkat-pRc/CMV-vector cells; lane 3: stable Jurkat-Fab3H7+L subclone 15/72-6.

FIG. 5. Radioimmunoprecipitation of cytoplasmic anti-MA Fab3H7 intrabody fragments

$\left[{ }^{35} \mathrm{~S}\right]$-cysteine-labeled proteins from cell lysates of stably transfected COS-1 cells were immunoprecipitated with rabbit anti-mouse IgG and were analyzed by electrophoresis on a 12.5\% SDS-PAGE gel. Lane I: molecular weight standards; lane 2: parental COS-1 cells; lane 3: COS-Fab3H7+L cells (clone 15/62); lane 4: COS-Fab3H7-L cells (clone 621); lane 5: COS-pRc/CMV-vector cells. Arrows indicate Fd heavy and light chains..

CMV vector cells (Fig. 3). Similar results were obtained using stably transfected Jurkat cells in place of COS-1 cells (data not shown).

The culture medium of individual stably transfected Jurkat-Fab3H7 + L cell subclones was used to determine if the secreted anti-MA Fab3H7 fragments were able to bind to recombinant MA coated onto ELISA plates. As shown in Fig. 4, medium from a representative JurkatFab3H7 $+\mathrm{L}$ subclone demonstrated binding to MA at 10-fold higher levels compared with the medium used from Jurkat-vector cells. These experiments demonstrate that the bicistronic expression vector pCMV-Fab-IRES allows the simultaneous expression of Fab3H7 Fd heavy and kappa chain fragments of the parent $3 \mathrm{H} 7$ hybridoma and that these Fab3 $\mathrm{H} 7$ fragments are able to bind HIV-1 MA.

\section{Expression of Cytoplasmic Anti-MA Fab3H7 Intrabody Fragments in Mammalian Cells}

Expression of the anti-MA Fab3H7 intrabodies in the cytoplasm of mammalian cells was initially determined by transient transfection with DEAEdextran of COS-1 cells using the pRc/CMV-
Fab3H7-L plasmid. In this construct, the native immunoglobulin leader sequences of the $\mathrm{Fd}$ heavy and kappa chains were removed and the individual chains were modified to contain a Kozak consensus sequence and an ATG initiation codon immediately preceding amino acid l of framework 1 of the heavy chain, and amino acid -4 of the leader sequence of the kappa chain (7). In these studies, abundant amounts of anti-MA Fab3H7 intrabody fragments were detected in the COS-1 cell lysate (data not shown). Cells that constitutively express the cytoplasmic anti-MA Fab3H7 intrabody fragments were then made by stable transfection of COS- 1 cells and CD $4^{+}$Jurkat $\mathrm{T}$ cells with the leaderless anti-MA pRc/ CMV-Fab3H7-L expressor plasmid. Radioimmunoprecipitation of cell lysates from randomly selected stable COS-Fab3H7-L cells with rabbit anti-mouse $\operatorname{IgG}$ demonstrated the correct size bands corresponding to the cytoplasmic Fdheavy and kappa chains with molecular weights of approximately 30 and $28 \mathrm{kd}$, whereas COSvector cells showed only nonspecific bands in this molecular weight range. However, as shown in Fig. 5, the cytoplasmic Fab3H7 fragments were detected in lesser amounts than the Fab3H7 fragments expressed in the endoplasmic reticulum (ER). 
A

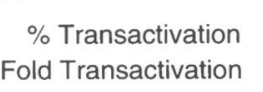

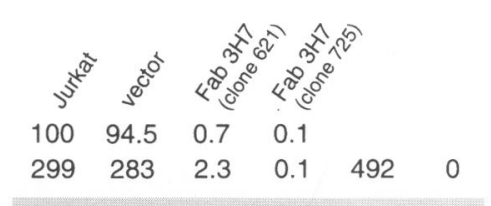

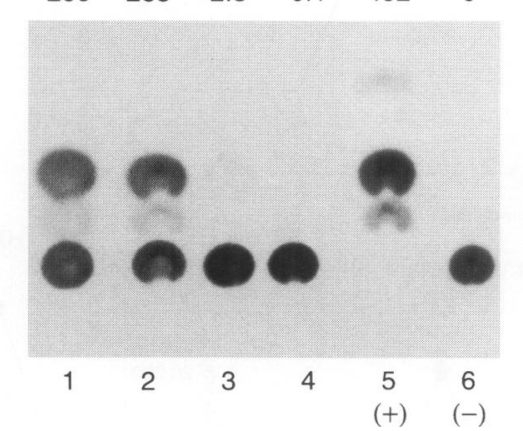

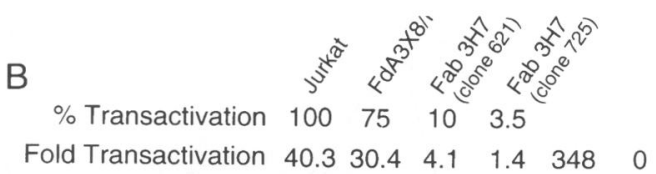

Fold Transactivation $40.3 \quad 30.4 \quad 4.1 \quad 1.4 \quad 348 \quad 0$

FIG. 6. Inhibition of CAT activity in stably transfected $\mathrm{CD4}^{+}$Jurkat $\mathrm{T}$ cells expressing cytoplasmic Fab3H7 intrabodies following infection with HIV-1 CAT virus

Seventy-two hours post-infection with $10,000 \mathrm{cpm} / \mathrm{ml}$ RT activity (pHXB $\Delta$ envCAT/pSVIIIenv), cell lysates were prepared and CAT activity was determined. (A) Lane l: Jurkat parental cells; lane 2, Jurkat-pRc/CMV-vector cells; lane 3: Jurkat-Fab3H7-L cells (clone 621-3); lane 4: Jurkat-Fab3H7-L cells (clone 725-3); lane 5: (+) control, CAT enzyme; lane 6: (-) control, no CAT enzyme. (B) Lane 1: Jurkat parental cells; lane 2: Jurkat FdA3X8/K3H7 cells; lane 3: Jurkat-Fab-3H7-L cells (clone 621-3); lane 4: Jurkat-Fab3H7-L cells (clone 725-3); lane 5, (+) control, CAT enzyme; lane $6,(-)$ control, no CAT enzyme.

\section{Inhibition of HIV-1 Proviral Gene Expression of $\mathrm{CD4}^{+}$Jurkat T Cells Stably Expressing Cytoplasmic Anti-MA Fab3H7 Intrabodies}

The ability of cytoplasmic Fab3H7 intrabodies to inhibit HIV-l gene expression was investigated using a HIV-1 CAT virus that has a chloramphenicol acetyltransferase (CAT) gene replacing the $n e f$ gene and a deletion in the env gene. Wildtype HIV-1 envelope was supplied in trans, so that the virions had the genetic capacity for only a single round of infectivity (32). Following infection and integration of viral DNA, newly synthesized Tat protein transactivates the expression of the CAT gene. If integration is blocked through the introduction of critical mutations in the integrase gene, Tat-mediated gene expression can still occur, presumably from unintegrated viral DNA; however, it is relatively inefficient $(40-44)$. In addition, it is generally observed that there is an insufficient level of HIV-1 gene expression to support a spreading viral infection $(40,41,43-45)$. Culture medium containing the HIV-1 CAT virus was used to infect stably transfected bulk populations of Jurkat-Fab3H7-L cells (data not shown) or randomly selected single-cell subclones that were obtained by limiting dilution. As shown in Fig. 6A, two random clones, $621 / 3$ and $725 / 3$, showed $>99 \%$ inhibition of CAT activity as compared to Jurkat control cells or a Jurkat-vector stable cell lines. In HIV-1 CAT virus-infected Jurkat cells that stably express an irrelevant $\mathrm{Fd}$ heavy chain in place of the $3 \mathrm{H} 7 \mathrm{Fd}$ fragment (Fd heavy chain chimera Jurkat-FdA $3 \times 8 / \mathrm{K} 3 \mathrm{H} 7$ cells), only $25 \%$ inhibition of CAT activity was seen (Fig. 6B). These results provide evidence that most of the binding energy and specificity is conferred by the MA-specific 3H7 heavy chain. In addition, the anti-MA Fab3H7 intrabody-expressing cells have the specific capacity to inhibit Tat-mediated CAT gene expression, which could occur as a result of inhibition of any critical step in the afferent arm of the virus life cycle that leads to integration of the HIV-1 provirus.

\section{Inhibition of HIV-1 Infection in CD4 $^{+}$Jurkat T Cells Stably Expressing Cytoplasmic Anti-MA Fab3H7 Intrabodies}

To determine if the stable Jurkat-Fab3H7-L cells were resistant to HIV-l infection, JurkatFab8H7-L subclones were infected with two isogeneic laboratory strains of HIV-l that differed only in the presence or absence of the accessory gene $v p u$, which has been shown to enhance the intracellular transport and maturation of env (46) as well as virion release (31). Two European, 

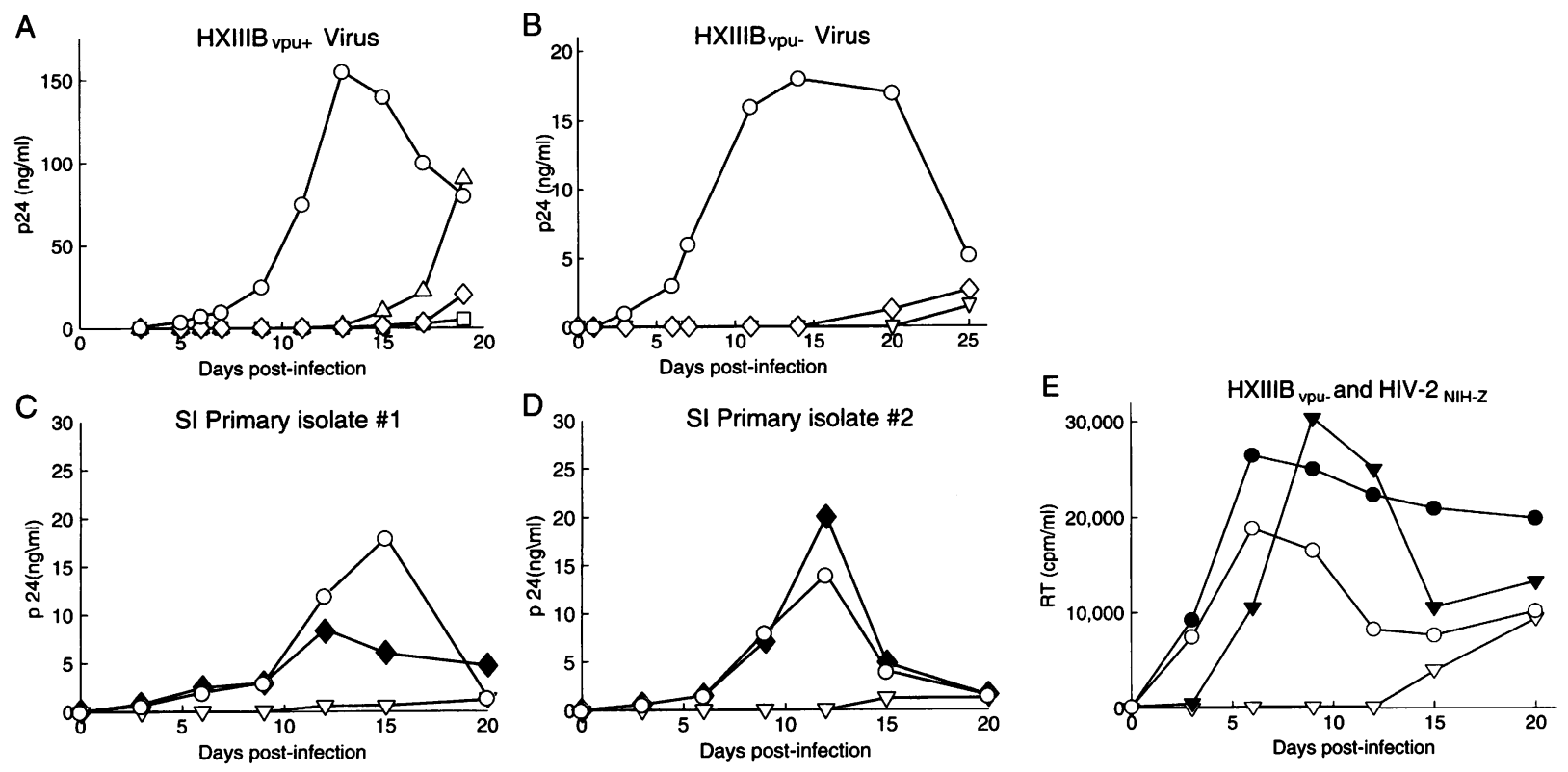

FIG. 7. Inhibition of $\mathrm{HIV}-1$ infection in stably transfected $\mathrm{CD4}^{+}$Jurkat $\mathrm{T}$ cells expressing cytoplasmic anti-MA Fab3H7 intrabodies

Subclones of $\mathrm{CD}^{+}$Jurkat-Fab3H7-L cells $\left(1 \times 10^{6}\right)$ were infected with either of two isogeneic laboratory strains of HIV-1 that differed in the presence or absence of the accessory gene, $v p u$ or two European SI primary isolates. Cell-free p24 levels were recorded on the indicated days. (A) Infection with HXIIIB vpu+ $_{\text {at }} 2000 \mathrm{cpm} / \mathrm{ml} \mathrm{RT} \mathrm{activ-}$ ity (MOI $\sim 0.5$ ) of Jurkat-pRc/CMV-vector cells (O), Jurkat-Fab3H7 (clone 621-1) ( $\triangle$ ), Jurkat-Fab3H7 (clone

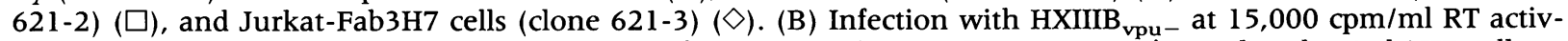
ity (MOI $\sim 6.5$ ) of Jurkat-pRc/CMV-vector cells $(O)$, Jurkat-Fab3H7 (clone 621-3) ( $)$ ), and Jurkat-Fab3H7 cells (clone 725-3) $(\nabla)$. (C and D) Parental Jurkat cells $(\diamond)$, Jurkat-vector cells $(\bigcirc)$, and Jurkat-Fab3H7 cells (clone 725-3) $(\nabla)\left(1 \times 10^{6}\right)$ were infected with $25 \mathrm{ng}$ p24 of two different European, syncytia-inducing (SI) primary isolates that were previously screened for their ability to infect parental CD4 ${ }^{+}$Jurkat T cells. (C) Infection with primary isolate \# 1. (D) Infection with primary isolate \#2. (E) Infection with HIV-2 NIH-Z $_{\text {or HXBIIIB }}$ vpu- $($ MOI $\sim 0.5)$. Open symbols represent infection with HXIIIB $_{\mathrm{vpu}-;}$; solid symbols, infection with HIV-2 NIH-Z; $_{\text {; }}$ circles, Jurkat-vector cells; and triangles, Jurkat-Fab3H7 cells (clone 723-5).

syncytium-including (SI) primary isolates that had been passaged on activated peripheral blood mononuclear cells (PBMCs) and screened for their ability to directly infect Jurkat cell lines were also tested (47). As shown in Fig. 7A, infection of three Jurkat-Fab3H7-L subclones with HXIIIB $_{\text {vpu }}+$ virus $($ MOI $\sim 0.5)$ resulted in a marked delay of virus infection (as measured by p24 release) over the 19 day experiment. In other experiments where infection of JurkatFab3H7-L subclones with HXIIIB ${ }_{\text {vpu }}$ virus (MOI $\sim 6.5$ ) was performed (Fig. 7B), a more profound inhibition of HIV-1 infection was seen over the 25-day experiment. Results in Fig. 7C and D demonstrate that Jurkat-Fab3H7-L cells infected with two SI primary isolates also showed marked inhibition of HIV-1 replication over the 20-day experiment as compared to parental Jurkat cells or stable Jurkat-vector cells. Finally, results in Fig. 7E demonstrate that the inhibition is specific for HIV-1 since very little inhibitory effect is seen where these stable cells are infected with HIV-2. HIV-1 and HIV-2 are divergent in amino acid sequences in this region of MA (48). Thus, these experiments demonstrated that actively dividing $\mathrm{CD}^{+}{ }^{+}$Jurkat $\mathrm{T}$ cells stably expressing anti-MA Fab intrabodies are resistant to HIV-1 infection when challenged with both laboratory strains and primary viral isolates. However, this resistance is relative and is not absolute with the stable cell lines and HIV-1 strains that were examined.

\section{Inhibition of HIV-1 Integration in $\mathrm{CD4}^{+}$Jurkat T Cells Stably Expressing Cytoplasmic Anti-MA Fab3H7 Intrabodies}

The mechanisms of inhibition of HIV-1 infection were investigated by examining HIV-1 integration and infectious virus formation separately. Effects on HIV-1 proviral (HXIIIB $\mathrm{vpu}_{-}$) integra- 


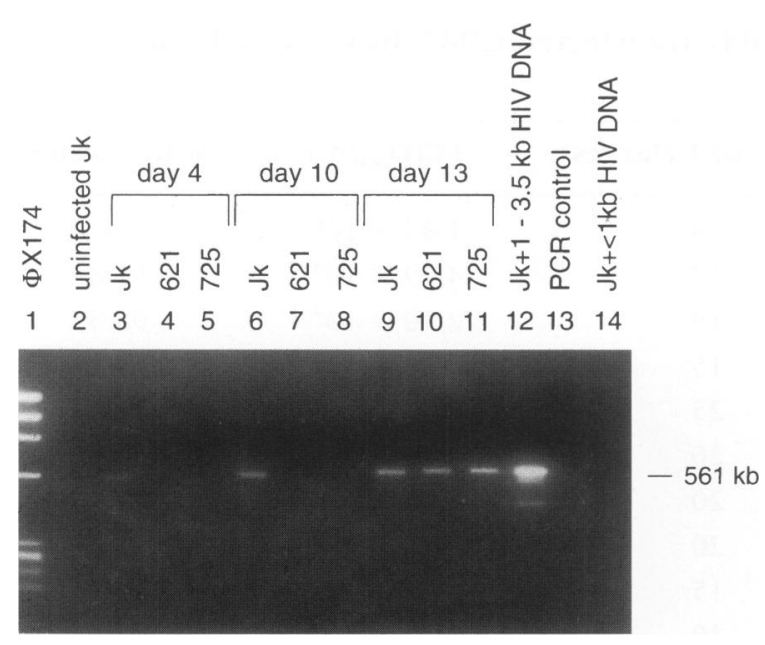

FIG. 8. HIV-1 DNA integration in Jurkat control and Jurkat-Fab3H7-L cells from an experiment similar to that in Fig. 7B

Lane 1: HaeIII digested $\phi$ X174 DNA molecular weight standards; lane 2: uninfected Jurkat cells; lanes 3, 6, 9: infected Jurkat cells; lanes 4, 7, 10: infected Jurkat-Fab3H7-L cells (clone 621-3); lanes 5, 8, 1 l: infected Jurkat-Fab3H7-L cells (clone 725-3). Lanes 2-5: Day 4; lanes 6-8: Day 10; lanes 9-11: Day 13; lane 12, uninfected Jurkat cells spiked with $1-3.5 \mathrm{~kb}$ fragments from $\mathrm{SacI} / \mathrm{XbaI}$ digested HXBc2 plasmid that contains the $\mathrm{SVC}_{\mathrm{vpu}}+\mathrm{HIV}-1$ provirus; lane 13: PCR primers alone, no cellular DNA; lane 14: same as lane 12 but spiked with proviral DNA fragments $<\mathrm{l} \mathrm{kb}$.

tion into the cellular DNA were explored using a PCR-based procedure in which viral-cellular DNA junction fragments of defined size (1$3.5 \mathrm{~kb}$ ) were isolated from a $1 \%$ agarose gel after restriction enzyme digestion of cellular DNA. After religation of the $5^{\prime}$ and $3^{\prime}$ LTR-cellular DNA fragments and PCR amplification of the ligated and reconstructed LTR fragments, a $561 \mathrm{bp}$ fragment is seen that represents integrated viral DNA (34). Southern blot analysis used a ${ }^{32} \mathrm{P}$-labeled LTR probe to confirm the identity of the PCR product (data not shown). As seen in Fig. 8, DNA from HIV-1-infected Jurkat cells (lane 3) show the $561 \mathrm{bp}$ integration product 4 days post-infection, whereas DNA from stable Jurkat-Fab3H7 subclones expressing the cytoplasmic anti-MA Fab3H7 intrabodies (lanes 4 and 5) do not. At 10 days post-infection, a strong integration band is seen only in the control cells (lane 6), and it is not seen in the anti-MA intrabody expressing subclones (lanes 7 and 8). The integration band is seen on Day 13 in the anti-MA Fab intrabody expressing subclones (lanes 10 and 11). Thus in these experiments, where multiple rounds of in- fection are occurring, integration was delayed but not prevented in the anti-MA Fab intrabodyexpressing cells. Similar analysis of DNA obtained from uninfected Jurkat cells spiked with viral DNA fragments obtained by restriction enzyme digestion outside of the $1-3.5 \mathrm{~kb}$ size range yielded no specific PCR products, indicating that the separation of DNA fragments of the LMP agarose gel and the extraction of these DNA fragments in the $1-3.5 \mathrm{~kb}$ region effectively removed viral DNA fragments outside the $1-3.5 \mathrm{~kb}$ range of DNA (lane 2). In addition, no specific signal was obtained if the $1-3.5 \mathrm{~kb}$ fragments were not ligated prior to PCR amplification, thus demonstrating that the $561 \mathrm{bp}$ fragments were not due to contaminating linear or circular viral DNA fragments (data not shown).

\section{Inhibition of Infectious Virus Formation in $\mathrm{CD4}^{+}$Jurkat $\mathrm{T}$ Cells Stably Expressing Cytoplasmic Anti-MA Fab3H7 Intrabodies}

The infectivity of HIV-1 virions released from the infected anti-MA-expressing Jurkat-Fab3H7-L cells was investigated by comparing the $\mathrm{TCID}_{50}$ of the cell-free culture supernatant normalized for Gag p24. The experiments were the same (Fig. 7A) or similar to those described in Fig. 7B-D. On the first day after infection of cells, when p24 was detectable in the supernatants, equal amounts (20-25 ng, depending on the experiment) of $\mathrm{p} 24$ were used to initiate infection of fresh $\mathrm{CD}^{+}{ }^{+} \mathrm{H} 9$ cells to determine the infectivity $\left(\mathrm{TCID}_{50}\right.$ units) of the virions (33). Supernatants from two to four subclones of HIV-1 challenged, Fab3H7-expressing Jurkat cells were examined. As shown in Table 1, marked inhibition of virion infectivity was seen with virions released from the Fab3H7 intrabody-expressing cells compared to control cells in all three viruses examined. This inhibition of virion infectivity ranged from $76 \%$ to $98.5 \%$, and most subclones showed $>93 \%$ inhibition compared to the virions released from control cells. Thus, these experiments demonstrate a significant decrease in the infectivity of the virions released from these HIV1-infected, Fab3H7 intrabody-expressing cells.

\section{DISCUSSION}

The results of these experiments demonstrate that the heavy and light chains of the anti-MA Fab intrabodies can self-assemble in the cytoplasm of mammalian cells into functional mole- 
TABLE 1. Infectivity of virus particles released from stably transfected $\mathrm{CD4}^{+}{ }^{+}$Jurkat $\mathrm{T}$ cell lines expressing anti-HIV-1 MA Fab3H7 intrabodies ${ }^{a}$

\begin{tabular}{|c|c|c|c|c|}
\hline Virus & Cell Line & Day of p24 Harvest & TCID $_{50} / \mathrm{ml}$ & \% Inhibition \\
\hline \multirow[t]{3}{*}{$\mathrm{HXIIIB}_{\mathrm{vpu}+}$} & Vector & 9 & $1.85 \times 10^{6}$ & - \\
\hline & Fab3H7 clone 621-1 & 17 & $4.09 \times 10^{4}$ & 97.8 \\
\hline & Fab3H7 clone 621-3 & 19 & $2.90 \times 10^{4}$ & 98.5 \\
\hline \multirow[t]{5}{*}{$\mathrm{HXBIII}_{\mathrm{vpu}-}$} & Vector & 15 & $2.60 \times 10^{6}$ & - \\
\hline & Fab3H7 clone 621-1 & 25 & $4.60 \times 10^{5}$ & 82.3 \\
\hline & Fab3H7 clone 621-3 & 20 & $6.30 \times 10^{6}$ & 76.0 \\
\hline & Fab3H7 clone $725-1$ & 20 & $1.60 \times 10^{5}$ & 93.8 \\
\hline & Fab3H7 clone $725-3$ & 20 & $1.16 \times 10^{5}$ & 96.0 \\
\hline \multirow[t]{5}{*}{ SI primary isolate \# 1} & Vector & 15 & $1.80 \times 10^{6}$ & - \\
\hline & Fab3H7 clone 621-1 & 30 & $1.15 \times 10^{5}$ & 93.6 \\
\hline & Fab3H7 clone 621-3 & 30 & $2.80 \times 10^{4}$ & 98.5 \\
\hline & Fab3H7 clone $725-1$ & 20 & $1.15 \times 10^{5}$ & 93.6 \\
\hline & Fab3H7 clone $725-3$ & 20 & $4.00 \times 10^{4}$ & 97.7 \\
\hline
\end{tabular}

$a_{-} 0.5,0.5$, and 0.2 M.O.I. of $\mathrm{HXIIIB}_{\mathrm{vpu}+}, \mathrm{HXIIIB}_{\mathrm{vpu}-}$, and SI primary isolate \#1 were used to infect cells respectively.

cules that can inhibit HIV-1 integration and infectious particle formation. Using the bicistronic expression vector pCMV-Fab-IRES, the Fd heavy and light chains of the $3 \mathrm{H} 7$ anti-MA Mab were expressed in near stoichiometric amounts, thereby resolving previously reported problems associated with using either separate promoters to drive expression of the Fd heavy and light chains (6) or using double drug selection (9). In addition, even in the reducing environment of the cytoplasm where inter- and intrachain disulfide bond formation may not be optimal (49), a sufficient number of stably expressed functional molecules are formed to inhibit HIV-1 infection. Thus, these technical advances significantly broaden the structural variations of functional cytoplasmic anti-HIV-1 intrabodies to include $\mathrm{sFv}$ (single chain), sFv-fusion proteins, and Fab molecules $(3-9,50)$.

The HIV-1 MA protein is involved in two critical stages of the viral life cycle: nuclear import of the viral preintegration complex and particle assembly. Interestingly, previous studies have shown that the MA NLS is dispensable for infection of replicating cells $(10-12,25,26)$. In the present study, however, in actively dividing $\mathrm{CD}^{+}{ }^{+} \mathrm{T}$ cells, the anti-MA Fab intrabodies directed against a carboxyl-terminal epitope associated with the Clade B HIV-1 genotype (39) were able to inhibit functions associated with this viral protein. Indeed, inhibition of HIV-1 infection with both laboratory strains and primary HIV-1 isolates was observed (Fig. 7 and Table 1). When examined separately, critical events in the early (afferent) and late (efferent) arms of the life cycle were inhibited.

The afferent arm of the HIV-1 life cycle was examined using an HIV-1 CAT virus with singleround infectivity (Fig. 6), and marked inhibition of Tat-mediated CAT activity was observed (Fig. 6). The mechanism of this inhibition was not determined in these studies; however, several processes may be involved. First, since most of the MA has been localized to the periphery of mature HIV-1 particles, where it is bound to the inner leaflet of the virus lipid bilayer (51) and in association with the envelope glycoprotein, it is possible that the anti-MA Fab intrabodies are infering with viral uncoating, a step in the viral life cycle that is poorly understood. Second, the anti-MA Fab intrabodies may be binding to the carboxyl-terminus of MA while it is a part of a high-molecular-weight preintegration complex and they may inhibit either reverse transcription indirectly or the transport of the preintegration complex through the nucleopore to the nucleus directly (52). In the latter case, however, because the HIV-1-infected Jurkat-Fab3H7-L cells are actively dividing in culture, the breakdown of the nuclear envelope at mitosis should allow the pre- 
integration complex to come in contact with cell chromosomes $(53,54)$. Therefore, for this direct mechanism of inhibition to occur, binding of the anti-MA Fab intrabodies to the MA-associated preintegration complex would have to render the complexes unstable. Decreased stability of viral RNA has been reported following HIV-1 entry in quiescent primary lymphocytes (36). Finally, it is possible that the anti-MA Fab intrabodies can prevent integration of the viral double-stranded DNA intermediate through steric interferences with other components of the preintegration complex (e.g., integrase). Indeed, a direct physical interaction between MA and integrase has been recently reported (26).

A marked decrease in the infectivity of virus particles released from the anti-MA Fab intrabody-expressing Jurkat-Fab3H7-L cells was seen when the cells were infected with either laboratory strains or two SI European primary isolates of HIV-1 (Fig. 7 and Table 1). Although the mechanism(s) of this inhibition were not uncovered in these studies, preliminary radioimmunoprecipitation studies of viral proteins from HIV1-infected Jurkat-Fab3H7-L cells showed no clear differences in the levels of $\mathrm{p} 55$ gag precursor or its cleavage product when cell lysates, supernatant, and cell-free pelleted virions were examined (data not shown). Thus, inhibition of a process other than $\mathrm{p} 55 \mathrm{gag}$ maturation could be occurring. Inhibition of envelope association with MA (55), MA dimerization (56), viral genomic RNA association with the p55 gag precursor, or tyrosine phosphorylation of MA by a virion-associated cellular protein kinase reported to lead to preferential targeting of phosphorylated MA to the nucleus of target cells (24-26) could also be involved.

When multiple rounds of infection were examined in HIV-1 challenge experiments (Fig. 8), less-integrated proviral DNA was seen in the intrabody-expressing cells than in control cells until Day 13. Since these experiments involve many cycles of HIV-1 replication, the appearance of less-integrated proviral DNA could be due to a block at any step in the replication cycle. Further experiments with single-round infections will be required to delineate the precise mode(s) of action for the anti-MA Fab intrabodies on the afferent and efferent arms of the replication cycle. Likewise, it is not known whether the "breakthrough" of viruses in the intrabody-producing cells is due to the development of mutant resistant viruses. Indeed, this epitope is not invariant even for the B Clade (57), and amino acid changes in this region are tolerated and generate infectious virus $(21,58)$. This potential problem may limit the use of anti-HIV-1 intrabodies as gene therapy reagents unless epitopes are targeted where mutations in the viral proteins result in loss of function and/or combinations of targets are chosen to cripple several steps in the viral life cycle simultaneously.

For the inhibitory effects of the anti-MA Fab intrabodies to be fully elucidated, further studies will be required in terminally differentiated nondividing cells such as macrophages (monocytes, tissue macrophages, dendritic cells, and microglial cells). The effects of the anti-MA Fab intrabodies on the nuclear import of the preintegration complex can be more accurately studied in these cells since the nucleopores remain intact $(10-12,25,26)$. Similar karyophilic properties have been shown for the accessory viral protein $\mathrm{Vpr}$, and in future studies using anti-MA Fab intrabody-expressing, nondividing cells, the relative contributions of the partly redundant MA and Vpr karyophilic localization signals could be examined in $\mathrm{Vpr}^{+}$and $\mathrm{Vpr}^{-}$viruses $(14,15)$. Indeed, the crucial role of these HIV-1-infected, nondividing cells in AIDS pathogenesis and in allowing the spread of HIV-1 infection makes them an attractive target for gene therapy and novel pharmacologic interventions.

In summary, anti-MA Fab intrabodies directed against a carboxy-terminal epitope on MA inhibit HIV-1 infection by disrupting both the afferent and efferent arms of the virus life cycle. This inhibitory effect is seen in $\mathrm{CD} 4^{+}$human $\mathrm{T}$ cells that are actively dividing. This combined early and late effect on the virus life cycle is unique among the anti-HIV-l intrabodies that have thus far been reported, including those directed against gp120 $(3,5,6)$, Tat $(7), \operatorname{Rev}(8,50)$, and RT (9). Two reasons for the potent inhibitory effects of the anti-HIV-1 intrabodies previously described and of the anti-MA intrabodies reported here may reside in the relative case of directing the intrabodies to relevant subcellular compartments and to different epitopes on a target protein (4). In future studies, bicistronic expression vectors as demonstrated here should be useful in the rapid evaluation of combination anti-HIV $\mathrm{sFv}$ intrabody-based gene therapy strategies (Fig. 1). Indeed, such combination target strategies will probably be needed in the clinical gene therapy setting, as recent treatment advances with combination anti-HIV-1 chemotherapy have shown $(59,60)$. If long-term protection of intrabody-expressing, transduced 
$\mathrm{CD}^{+}$and differentiated $\mathrm{CD} 34^{+}$stem cells is to be achieved, these cells will have to give rise to HIV-1-resistant progeny cells that are capable of expanding in the host and allow for long-term immunologic reconstitution.

\section{ACKNOWLEDGMENTS}

We thank Drs. Alan Engelman, Joseph Sodroski, and Jennifer Richardson for their critical review of the manuscript and helpful comments. This work was supported by NIH grants P30 AI28691 (Center for AIDS Research), P30 CA06516 (Cancer Center Grant), AI28785, AI33802, AI31782, Claudia Adams Barr Innovative Basic Science Program, and a gift from the G. Harold and Leila Y. Mathers Charitable Foundation. A portion of this work was also funded by Virus Research Institute, Cambridge, MA.

\section{REFERENCES}

1. Baltimore D. (1988) Intracellular immunization. Nature 335: 395-396.

2. Gilboa E, Smith C. (1994) Gene therapy for infectious diseases: The AIDS model. Trends in Genet. 10: 139-144.

3. Marasco WA, Haseltine WA, Chen SY. (1993) Design, intracellular expression, and activity of a human anti-human immunodeficiency virus type $1 \mathrm{gp} 120$ single-chain antibody. Proc. Natl. Acad. Sci. U.S.A. 90: 7889-7893.

4. Marasco WA. (1995) Intracellular antibodies (intrabodies) as research reagents and therapeutic molecules for gene therapy. Immunotechnology 1: 1-19.

5. Chen S-Y, Khouri Y, Bagley J, Marasco WA. (1994) Combined intra- and extracellular immunization against human immunodeficiency virus type 1 infection with a human anti-gpl20 antibody. Proc. Natl. Acad. Sci. U.S.A. 91: 5932-5936.

6. Chen S-Y, J. Marasco WA. (1994) Intracellular antibodies as a new class of therapeutic molecules for gene therapy. Hum. Gene Ther. 5: 595-601.

7. Mhashilkar A, Bagley J, Chen S-Y, Szilvay AM, Helland DG. Marasco WA. (1995) Inhibition of HIV-1 Tat-mediated LTR transactivation and HIV-1 infection by anti-Tat single chain intrabodies. $E M B O \mathrm{~J}$. 14: 1542-1551.

8. Duan L, Bagasra O, Laughlin MA, Oakes JW, Pomerantz RJ. (1994) Potent inhibition of human immunodeficiency virus type 1 replication by an intracellular anti-Rev singlechain antibody. Proc. Natl. Acad. Sci. U.S.A. 91: 5075-5079.

9. Maciejewski JP, Weichold FF, Young NS, et al. (1995) Intracellular expression of antibody fragments against HIV reverse transcriptase prevents HIV infection in vitro. $\mathrm{Na}$ ture Mag. 1: 667-673.

10. Bukrinsky MI, Haggerty S, Dempsey MP, et al. (1993) A nuclear localization signal within HIV-1 matrix protein that governs infection of non-dividing cells. Nature 365: 666-669.

11. von Schwedler U, Kornbluth RS, Trono D. (1994) The nuclear localization signal of the matrix protein of human immunodeficiency virus type 1 allows the establishment of infection in macrophages and quiescent T lymphocytes. Proc. Natl. Acad. Sci. U.S.A. 91: 69926996.

12. Bukrinsky MI, Sharova N, McDonald TL, Pushkarskaya T, Tarpley WG, Stevenson M. (1993) Association of integrase, matrix, and reverse transcriptase antigens of human immunodeficiency virus type 1 with viral nucleic acids following acute infection. Proc. Natl. Acad. Sci. U.S.A. 90: 6125-6129.

13. Sharova N, Bukrinskaya A. (1991) pl7 and pl7-containing gag precursors of input human immunodeficiency virus are transported into the nuclei of infected cells. AIDS Res. Hum. Retroviruses 7: 303-306.

14. Emerman $M$, Bukrinsky $M$, Stevenson $M$. (1994) HIV-1 infection of non-dividing cells. Nature 369: 107-108.

15. Heinzinger NK, Bukrinsky MI, Haggerty SA, et al. (1994) The Vpr protein of human immunodeficiency virus type 1 influences nuclear localization of viral nucleic acids in nondividing host cells. Proc. Natl. Acad. Sci. U.S.A. 91: 7311-7315.

16. Spearman P, Wang J-J, Vander Heyden N, Ratner L. (1994) Identification of human immunodeficiency virus type 1 gag protein dominates essential to membrane binding and particle assembly. J. Virol. 68: 3232-3242.

17. Zhou W, Parent LJ, Wills JW, Resh MD. (1994) Identification of a membrane-binding domain within the amino terminal region of human immunodeficiency virus type 1 gag protein which interacts with acidic phospholipids. J. Virol. 68: 2556-2569.

18. Bryant M, Ratner L. (1990) Myristoylationdependent replication and assembly of hu- 
man immunodeficiency virus 1. Proc. Natl. Acad. Sci. U.S.A. 87: 523-527.

19. Göttlinger HG, Sodroski JG, Haseltine WA. (1989) Role of capsic precursor processing and myristoylation in morphogenesis and infectivity of human immunodeficiency virus type 1. Proc. Natl. Acad. Sci. U.S.A. 86: 5781-5785.

20. Pal R, Reitz MS Jr, Tschachler, Gallo RC, Sarngadharan MG, Di Marzo Veronese F. (1990) Myristoylation of gag proteins of HIV-1 plays an important role in virus assembly. AIDS Res. Hum. Retroviruses 6: 721-730.

21. Dorfman T, Mammano F, Haseltine WA, Göttlinger HG. (1994) Role of the matrix protein in the virion association of the human immunodeficiency virus type 1 envelope glycoprotein. J. Virol. 68: 1689-1696.

22. Yu X, Yuan X, Matsuda Z, Lee T-H, Essex M. (1992) The matrix protein of human immunodeficiency virus type 1 is required for incorporation of viral envelope protein into mature virions. J. Virol. 66: 4966-4971.

23. Yu X, Yu Q-C, Lee T-H, Essex M. (1992) The $C$ terminus of human immunodeficiency virus type 1 matrix protein is involved in early steps in virus life cycle. J. Virol. 66: 5667-5670.

24. Bukrinskaya AG, Ghorpade A, Heinzinger NK, Smithgall E, Lewis RE, Stevenson $M$. (1996) Phosphorylation-dependent human immunodeficiency virus type 1 infection and nuclear targeting of viral DNA. Proc. Natl. Acad. Sci. U.S.A. 93: 367-371.

25. Gallay P, Swingler S, Aiken C, Trono D. (1995) HIV-1 infection of nondividing cells: C-terminal tyrosine phosphorylation of the viral matrix protein is a key regulator. Cell 80: $379-388$

26. Gallay P, Swingler S, Song J, Bushman F, Trono D. (1995) HIV nuclear import is governed by the phosphotyrosine-mediated binding of matrix to the core domain of integrase. Cell 83: 569-576.

27. Bagley J, Dillon PJ, Rosen C, Robinson J, Sodroski J, Marasco WA. (1994) Structural characterization of broadly neutralizing human monoclonal antibodies against the CD4 binding site of HIV-1 gpl20. Mol. Immunol. 31: 1149-1160.

28. Marasco WA, Bagley J, Zani C, et al. (1992) Characterization of the CDNA of a broadly reactive neutralizing human anti-gpl 20 monoclonal antibody. J. Clin. Invest. 90: 1467-1478.

29. Niedrig $M$, Hinkula $J$, Weigelt $W$, et al. (1989) Epitope mapping of monoclonal an- tibodies against human immunodeficiency virus type 1 structural proteins by using peptides. J. Virol. 63: 3525-3528.

30. Kabat EA, Wu TT, Perry HM, Gottesman KS, Foeller C. (1991) Tabulation and analysis of amino acid and nucleic acid sequences of precursors, V-regions, C-regions, J-chain, $\mathrm{T}$ cell receptors for antigen, T-cell surface antigens, Thy-1, complement, c-reactive protein, thymopoietin, integrins, post-gamma globulin, $\alpha_{2}$-macroglobulins and other related proteins. In: Sequences of Proteins of Immunological Interest. U.S. Department of Health and Human Services, NIH Publication No. 91-3242, Washington, DC.

31. Göttlinger HG, Dorfman T, Cohen EA, Haseltine WA. (1993) Vpu protein of human immunodeficiency virus type 1 enhances the release of capsids produced by gag gene constructs of widely divergent retroviruses. Proc. Natl. Acad. Sci. U.S.A. 90: 7381-7385.

32. Helseth E, Kowalski M, Gabuzda D, Olshevsky U, Haseltine W, Sodroski J. (1990) Rapid complementation assays measuring replicative potential of human immunodeficiency virus type 1 envelope glycoprotein mutants. J. Virol. 64: 2416-2420.

33. Johnson VA, Byington RE. (1990) Quantitative Assays for Virus Infectivity. In: Aldovini A, Walker BD (eds), Techniques in HIV Research. Stockton Press, Stockholm, NY, pp. 71-96.

34. Li G, Simm M, Potash MJ, Volsky DJ. (1993) Human immunodeficiency virus type 1 DNA synthesis, integration, and efficient viral replication in growth-arrested T cells. J. Virol. 67: 3969-3977.

35. Innis MA, Gelfand DH, Sninsky JJ, White TJ. (eds.) (1990) PCR Protocols. In: A Guide to Methods and Applications. Academic Press, San Diego, CA.

36. Zack JA, Arrigo SJ, Weitsman SR, Go AS, Haislip A, Chen ISY. (1990) HIV-1 entry into quiescent primary lymphocytes: Molecular analysis reveals a labile, latent viral structure. Cell 61: 213-222.

37. Duke GM, Hoffman MA, Palmenberg AC. (1992) Sequence of structural elements that contribute to efficient encephalomyocarditis virus RNA translation. J. Virol. 66: 1602-1609.

38. Elroy-Stein O, Fuerst TR, Moss B. (1989) Cap-independent translation of mRNA conferred by encephalomyocarditis virus $5^{\prime}$ sequence improves the performance of the vaccinia virus/bacteriophage T7 hybrid ex- 
pression system. Proc. Natl. Acad. Sci. U.S.A. 86: 6126-6130.

39. Louwagie J, McCutchan FE, Peeters M, et al. (1993) Phylogenetic analysis of gag genes from 70 international HIV-1 isolates provides evidence for multiple genotypes. AIDS 7: 769-780.

40. Ansari-Lari MA, Donehower LA, Gibbs RA. (1995) Analysis of human immunodeficiency virus type 1 integrase mutants. Virology 211: 332-335.

41. Engelman A, Englund G, Orenstein JM, Martin MA, Craigie R. (1995) Multiple effects of mutations in human immunodeficiency virus type 1 integrase on viral replication. J. Virol. 69: 2729-2736.

42. Lewis P, Hensel M, Emerman M. (1992) Human immunodeficiency virus infection of cells arrested in the cell cycle. EMBO J. 11: 3053-3058.

43. Sakai H, Kawamura M, Sakuragi J-I, et al. (1993) Integration is essential for efficient gene expression of human immunodeficiency virus type 1. J. Virol. 67: 1169-1174.

44. Wiskerchen M, Muesing MA. (1995) Human immunodeficiency virus type 1 integrase: Effects of mutations on viral ability to integrate, direct viral gene expression from unintegrated viral DNA templates, and sustain viral propagation in primary cells. J. Virol. 69: 376-386.

45. Stevenson $M$, Haggerty $S$, Lamonica CA, Meier CM, Welch S-K, Wasiak AJ. (1990) Integration is not necessary for expression of human immunodeficiency virus type 1 protein products. J. Virol. 64: 2421-2425.

46. Willey RD, Maldraelli F, Martin MA, Strebel K. (1992) Human immunodeficiency virus type $1 \mathrm{vpu}$ protein regulates the formation of intracellular gp120-CD4 complexes. J. Virol. 66: 226-234.

47. Fenyö EM, Albert J, Åsjö B. (1989) Replication capacity, cytopathic effect and cell tropism of HIV. AIDS 3: S5-S12.

48. Blomberg J, Medstrand P. (1990) A sequence of the carboxyl terminus of the HIV-1 matrix protein is highly similar to sequences in membrane-associated proteins of other RNA viruses: Possible functional implications. New Biologist 2: 1044-1046.

49. Biocca S, Ruberti F, Tafani M, PierandreiAmaldi P, Cattaneo A. (1995) Redox state of single chain Fv fragment targeted to the endoplasmic reticulum, cytosol and mitochondria. Biotechnology 13: 1110-1115.

50. Duan L, Zhang H, Oakes JW, Bagasra O,
Pomerantz RJ. (1994) Molecular and virological effects of intracellular anti-rev singlechain variable fragments on the expression of various human immunodeficiency virus-1 strains. Hum. Gene Ther. 5: 1315-1324.

51. Gelderblom HR, Hausmann EHS, Özel $M$, Pauli G, Koch MA. (1987) Fine structure of human immunodeficiency virus (HIV) and immunolocalization of structural proteins. Virology 156: 171-176.

52. Bukrinsky MI, Sharova N, Dempsey MP, et al. (1992) Active nuclear import of human immunodeficiency virus type 1 preintegration complexes. Proc. Natl. Acad. Sci. U.S.A. 89: $6580-6584$.

53. Lewis PF, Emerman M. (1994) Passage through mitosis is required for oncoretroviruses but not for human immunodeficiency virus. J. Virol. 68: 510-516.

54. Roe TY, Reynolds TC, Yu G, Brown PO. (1993) Integration of murine leukemia virus DNA depends on mitosis. EMBO J. 12: 2089-2108.

55. Lodge $R$, Göttlinger $H$, Gabuzda D, Cohen EA, Lemay G. (1994) The intracytoplasmic domain of gp4l mediates polarized budding of human immunodeficiency virus type 1 in MDCK cells. J. Virol. 68: 4857-4861.

56. Morikawa $\mathrm{Y}$, Kishi $\mathrm{T}$, Zhang WH, Nermut MV, Hockley DJ, Jones IM. (1995) A molecular determinant of human immunodeficiency virus particle assembly located in matrix antigen p17. J. Virol. 69: 4519-4523.

57. Myers G, Korber B, Wain-Hobson S, Jeang $\mathrm{K}-\mathrm{T}$, Henderson LE, Pavlakis GN. (1994) Human Retroviruses and AIDS: A Compilation and Analysis of Nucleic Acid and Amino Acid Sequences. Los Alamos National Laboratory, Los Alamos, New Mexico.

58. Freed EO, Orenstein JM, Buckler-White AJ, Martin MM. (1994) Single amino acid changes in the human immunodeficiency virus type 1 matrix protein block virus particle production. J. Virol. 68: 5311-5320.

59. Choo V. (1995) Combination superior to zidovudine in Delta trial. Lancet 346: 895.

60. Collier AC, Coombs RW, Schoenfeld DA, Bassett R, Baruch A, Corey L. (1995) Extended treatment with saquinavir (SAQ), zidovudine (ZDV), and zalcitabine (ddc) vs SAQ and ZDV vs ddc and VDZ. In: Program and Abstracts of the 35th Interscience Conference on Antimicrobial Agents and Chemotherapy, San Francisco, September 17-20, 1995. American Society for Microbiology, Washington, D.C. 236 [Abstract]. 